\title{
Does neuroinflammation turn on the flame in Alzheimer's disease? Focus on astrocytes
}

\author{
Luca Steardo Jr. ${ }^{1}$, Maria R. Bronzuoli ${ }^{2}$, Aniello lacomino ${ }^{3}$, Giuseppe Esposito ${ }^{2}$, \\ Luca Steardo ${ }^{2}$ and Caterina Scuderi ${ }^{2 *}$ \\ 'Department of Psychiatry, University of Naples SUN, Naples, Italy, ${ }^{2}$ Department of Physiology and Pharmacology "Vittorio \\ Erspamer", Sapienza University of Rome, Rome, Italy, ${ }^{3}$ Faculty of Psychology, University of Rome "G. Marconi”, Rome, Italy
}

Data from animal models and Alzheimer's disease (AD) subjects provide clear evidence for an activation of inflammatory pathways during the pathogenetic course of such illness. Biochemical and neuropathological studies highlighted an important cause/effect relationship between inflammation and AD progression, revealing a wide range of genetic, cellular, and molecular changes associated with the pathology. In this context, glial cells have been proved to exert a crucial role. These cells, in fact, undergo important morphological and functional changes and are now considered to be involved in the onset and progression of $A D$. In particular, astrocytes respond quickly to pathology with changes that have been increasingly recognized as a continuum, with potentially beneficial and/or negative consequences. Although it is now clear that activated astrocytes trigger the neuroinflammatory process, however, the precise mechanisms have not been completely elucidated. Neuroinflammation is certainly a multi-faceted and complex phenomenon and, especially in the early stages, exerts a reparative intent. However, for reasons not yet all well known, this process goes beyond the physiologic control and contributes to the exacerbation of the damage. Here we scrutinize some evidence supporting the role of astrocytes in the neuroinflammatory process and the possibility that these cells could be considered a promising target for future AD therapies.

Keywords: glia, astrocyte, neuroinflammation, neurodegeneration, Alzheimer's disease

\section{Inflammation in Alzheimer's Disease}

Alzheimer's disease (AD) is a neurodegenerative disorder characterized by memory loss and significant cognitive decline with impaired activities of daily living (Goedert and Spillantini, 2006). Despite all scientific efforts, medications currently used provide only modest and transient benefits to a subset of patients and effective pharmacotherapeutic options are lacking. Histopathologically, the hallmarks of $\mathrm{AD}$ are extracellular deposits of beta amyloid $(\mathrm{A} \beta)$ fibrils in senile plaques (SP) and intraneuronal neurofibrillary tangles (NFT). NFT are filamentous inclusions composed of hyperphosphorylated forms of the microtubule-associated protein tau (Blennow et al., 2006). $\mathrm{A} \beta$ results from the abnormal proteolytic cleavage of amyloid-precursor protein (APP) by the sequential action of beta- and gamma-secretase. The widely accepted A $\beta$ cascade hypothesis suggests that this peptide is the direct cause of neurodegeneration, synaptic loss, and cognitive decline in AD (Selkoe, 1996). Even if several biochemical mechanisms have been proposed, including production of reactive oxygen species, disruption of calcium homeostasis, activation 
of Wnt pathway, excitotoxicity, activation of apoptotic pathways, neuronal degeneration, and neurotransmitter deficits, the precise role of abnormal protein aggregates in the pathogenesis of $\mathrm{AD}$ remains to be clarified (Huang and Jiang, 2009; Welsh-Bohmer and White, 2009; Querfurth and LaFerla, 2010). Interestingly, data from animal models and human autopsies revealed that both SP and NFT are co-localized with activated glial cells, suggesting that reactive gliosis might exert a key pathogenetic role in $\mathrm{AD}$ (Craft et al., 2006). A $\beta$ peptides, probably through the main involvement of non-neuronal cells, promote neuroinflammation, accounting for the synthesis of different cytokines, and proinflammatory mediators (Mrak and Griffin, 2001; Tuppo and Arias, 2005). Recent evidence assigns to astrocyte dysfunctions a critical role in aging and in several neurodegenerative diseases, including AD. It is now clear that astrocytes are essential in the control of cerebral homeostasis. However, several brain injuries, including $A \beta$ deposition, modify their physiological functioning and astrocyte acquire a reactive phenotype (Verkhratsky et al., 2014). Activation of these cells is fundamentally a protective response aimed at removing injurious stimuli. However, uncontrolled and prolonged activation goes beyond physiological control and detrimental effects override the beneficial ones. In this condition, astrocytes foster neuroinflammatory response, accounting for the synthesis of different cytokines and proinflammatory mediators. After their release, pro-inflammatory signal molecules act, in an autocrine way, to self perpetuate reactive gliosis and, in a paracrine way, to kill neighboring neurons expanding the neuropathological damage (Mrak and Griffin, 2001; Pekny et al., 2014).

In this context, it is important to highlight that inflammatory process, once initiated, may contribute independently to neural dysfunction and cell death, thereby establishing a self-fostering vicious cycle, by which the inflammation represents a substantial cause of further neurodegeneration (Block and Hong, 2005; Glass et al., 2010). Therefore, it is reasonable to assume that early combination of neuroprotective and anti-inflammatory treatments aimed at restoring astrocyte functions may represent an appropriate approach to treat $\mathrm{AD}$, whereas the treatment of only one pathological process might even worsen the others (Scuderi et al., 2014a).

A growing body of evidence shows the remarkable complexity of inflammatory mechanisms in $\mathrm{AD}$ and how these mechanisms are often driven by alterations of glial cells functioning. Such complexity encourages to perform additional investigations in order to better clarify the mechanisms involved with the aim to develop appropriate therapeutics.

Can astrocytes become the target for new drugs? In the last decade, the neuron-centric vision of neuropsychiatric diseases has undergone considerable changes. Indeed, it is now clear that the non-neuronal cells could be involved in the pathogenesis and progression of many diseases due to their important and active roles exerted in the brain physiological and pathological conditions. Therefore, these cells could not be considered simple co-stars in the drama of neuropsychiatric disorders, including neurodegeneration.

Glial cells are non-excitable cells of the central nervous system (CNS). These cells are a highly heterogeneous population, responsible for many important brain functions (Doens and Fernández, 2014; Öngür et al., 2014; Hol and Pekny, 2015; Rodríguez-Arellano et al., 2015). The oligodendrocytes, for example, envelop axons with myelin and provide neurons with homeostatic support, and progenitor cells expressing proteoglycan NG2 most likely represent a reservoir of myelinating cells (Fröhlich et al., 2011; Walhovd et al., 2014). The microglial cells are regarded to be the innate immune cells in the CNS. They get activated in response to any type of brain injury, producing a wide range of proor anti-inflammatory mediators (Gundersen et al., 2015). Astrocytes are definitely the most abundant and heterogeneous type of glial cells in the CNS. Indeed, their morphology differs largely depending on their development stage, subtype, and localization. For example, the most abundant astrocytes of the gray matter are the protoplasmic ones, which exhibit short branches, whereas the fibrous astrocytes are present in the white matter and exhibit long unbranched processes (Verkhratsky and Parpura, 2015). It is well-proved that astrocytes control the brain homeostasis and allow neurons to functioning; they are an essential neuro-supportive cell type in brain, responsible for a massive number of homeostatic tasks in the CNS (Verkhratsky and Butt, 2013). Indeed, astrocytes finely control the environment by regulating $\mathrm{pH}$, ion homeostasis, blood flow, and modulate oxidative stress (Deitmer and Rose, 1996; Wilson, 1997; Iadecola and Nedergaard, 2007; Obara et al., 2008). In addition, these cells importantly contribute to synaptogenesis and dynamically modulate information processing and signal transmission, regulate neural and synaptic plasticity, and provide trophic and metabolic support to neurons (Perea et al., 2009; Sofroniew, 2014). On the basis of all these considerations, it is reasonable to assume that alterations in some of these important neuro-supportive functions can result in injurious consequences for the brain (Bélanger and Magistretti, 2009).

It has been well established that brain insults trigger a specific astroglial reaction represented by a complex morphofunctional remodeling (Sun and Jakobs, 2012). Astrocytes, together with microglia, are the cellular component of the resident innate immune system in the CNS. They act as crucial effectors of the neuroinflammatory response (Ransohoff and Brown, 2012). Indeed, astrocytes rapidly act in response to pathology undergoing important changes in their morphology and functioning (Sofroniew and Vinters, 2010; Scuderi et al., 2013; Rossi, 2015). This reactive state starts with the intention to control and remove the brain damage, however it has deleterious consequences. In fact, reactive gliosis is a self-perpetuating process which, at the end, exacerbates the injury and, on another hand it represents a non-physiologic state in which astrocytes lose their helpful properties. These events are particularly patent in $\mathrm{AD}$ brain and Alzheimer himself was able to recognize, in autopsied specimens, a marked activation of astroglial cells and described a manifest inflammatory status (Alzheimer, 1907). Data from both humans and animal models of $\mathrm{AD}$ have demonstrated that reactive astrocytes co-localize with SP and NFT (Lukiw and Bazan, 2000; Armstrong, 2009; Rodríguez et al., 2009) suggesting that the primary aim of this peculiar localization 
is probably the creation of a barrier between healthy and injured tissue.

Additionally, accumulating data shows the relevant role of astrocytes in $\mathrm{A} \beta$ pathogenesis of $\mathrm{AD}$. Numerous debates have discussed whether astrocytes uptake $A \beta$ from the extracellular space or they could synthesize $A \beta$ de novo.

Astrocytes possess tools to internalize and metabolize $A \beta$ in vivo. They express the receptor for advanced glycation end product (RAGE) which binds $A \beta$, and possess a complex apparatus able to take up $A \beta$ (Wyss-Coray et al., 2003). So, the notion that astrocytes phagocytose $A \beta$ from the extracellular space is reinforced by a number of investigations, which proved that $A \beta$ was taken up by astrocytes for lysosomal degradation in order to maintain $A \beta$ homeostasis (Funato et al., 1998). It has been postulated that this complex machinery makes astrocytes the preferential type of glial cells liable to remove $A \beta$ (Nagele et al., 2003; Wyss-Coray et al., 2003; Koistinaho et al., 2004). In other studies, a lower responsiveness to $\mathrm{A} \beta$ in human astrocytes from $\mathrm{AD}$ cases was reported, suggesting that SP formation in the extracellular space might be subsequent to insufficient clearance of A $\beta$ by astrocytes (Mulder et al., 2012). APP and $\mathrm{BACE} 1$ overexpression in astrocytes may result in $\mathrm{A} \beta$ synthesis de novo (Zhao et al., 2011). It was reported an enhanced BACE1 production in reactive astrocytes, supporting the notion that $A \beta$ accumulation in the extracellular space could be secondary to its production and release by activated astrocytes. Therefore, based upon this evidence it is possible to assert that astrocytes may have a dual role in either clearing and producing $A \beta$.

On the other side, exposure to $A \beta$ causes deleterious consequences on astrocyte functioning. Indeed, these cells alter their morphology with a marked increase in the expression of the glial fibrillary acidic protein (GFAP), a recognized marker of astrocyte reactivity (Chow et al., 2010; Scuderi et al., 2014a). In parallel, $A \beta$ challenge provokes alterations of calcium homeostasis, energetic modification, and degeneration of cocultured neurons (Malchiodi-Albedi et al., 2001; Abramov et al., 2004; Chow et al., 2010; Scuderi et al., 2011, 2012). Lastly, A $\beta$ insult also results in increased oxidative and nitrosative stress (Frank-Cannon et al., 2009). It has been demonstrated that $\mathrm{A} \beta$ accumulation in SP causes over-expression of a number of inflammation-related factors, such as nitric oxide (NO) interleukin (IL)- $1 \alpha, \mathrm{IL}-1 \beta$, and tumor necrosis factor (TNF)- $\alpha$ (Li et al., 2003; Esposito et al., 2006). An increasing body of evidence demonstrates that NO represents one of the major effectors of neuronal cell death through mitochondrial depolarization (Solenski et al., 2003), while IL-1 $\beta$ enhances activation of caspase3 , an enzyme implicated in hippocampal neuron apoptotic death in aged rats (Lynch and Lynch, 2002). Similarly, TNF- $\alpha$ has been demonstrated to be involved in neuronal apoptosis induced by $\mathrm{A} \beta$, activating the caspase-cascade, through the interaction with its specific type 1 receptor (Li et al., 2004a).

Transgenic APP (SWE) (Tg2576) mice, which over-express the human APP gene, show high levels of interferon- $\gamma$ and IL-12 mRNA, as well as their protein production, and such an increase was found in the reactive astrocytes surrounding $A \beta$ deposits (Abbas et al., 2002). Some authors demonstrated that some of these effects may be due to alterations in astrocyte transcription factors. For example, the CCAAT-enhancer binding protein (C/EBP) family of transcription factors, which regulates or coregulates a wide range of inflammatory mediators, is considerably higher in reactive astrocytes surrounding $A \beta$ deposits of $A D$ cortex in comparison with non-AD age matched controls ( $\mathrm{Li}$ et al., 2004b).

In addition it was demonstrated that astrocytic NF- $\kappa \mathrm{B}$ is activated after $A \beta$ exposure, causing an increased expression and release of a variety of inflammatory molecules including IL- $1 \beta$ and IL-6 (Bales et al., 1998). Moreover, the activation of NF- $\kappa B$ in astrocytes is also responsible in mediating the inflammatory process through the expression of adhesion molecules and chemokines which allow the invasion by peripheral leukocytes (Moynagh, 2005). Although the impact of astroglial inactivation of NF- $\kappa B$ has not been established in AD mouse models, recent evidence demonstrates that blockage of NF- $\kappa B$ transcriptional activity in astrocytes can extensively reduce inflammation and improve recovery, thus suggesting that inhibition of NF- $\kappa$ B in astrocytes may be regarded as a potential therapy for $\mathrm{AD}$ (Medeiros and LaFerla, 2013).

Among the many released mediators, S100B represents a key factor during neuroinflammation. This small peptide is almost exclusively produced by astrocytes and, under physiological conditions, it is a neurotrophin responsible for survival, development, and function of neurons (Donato, 2003). In AD, but also in Down's syndrome (whose subjects often develop a precocious AD-like dementia), in Parkinson's disease, and in subjects with severe brain trauma, S100B is over-expressed and its levels correlate with the progression of the pathology (Mrak et al., 1996; Sheng et al., 2000). A similar correlation is detectable in the brain of APPV717F, transgenic mice which over-express a human APP minigene encoding a familial AD mutation. In APPV717F is evident an age-related increase in tissue levels of both APP and S100B mRNA and such an increase precedes the appearance of neuritic plaques (Sheng et al., 2000). Lastly, by using S100B-overexpressing transgenic and S100B knockout mice intracerebroventricular injected with human oligomeric $A \beta_{1-42}$, it was established a relationship between S100B levels and susceptibility to $\mathrm{AD}$-relevant neuroinflammation and neuronal dysfunction. Indeed, after $A \beta$ infusion inflammatory reaction in S100B-overexpressing transgenic mice was markedly higher than in knock-out or wild-type mice (Craft et al., 2005).

In addition, electrophysiological and behavioral investigations demonstrated that S100B affects long-term synaptic plasticity and impairs cognitive tasks (Gerlai, 1998; Nishiyama et al., 2002). All these considerations emphasize the assumption that $\mathrm{S} 100 \mathrm{~B}$ up-regulation may result in deleterious consequences and that early targeting of this protein could be beneficial in preventing or slowing $\mathrm{AD}$ progression. Finally, to further support the assumption that a protracted reactive gliosis is importantly implicated in the pathobiology of $\mathrm{AD}$, proton resonance spectroscopy consistently provided evidence of a significant increase of myoinositol (an astroglial marker) in brain areas of both mild cognitive impairment (MCI) and AD patients. Such an increase, according to some studies, have been reported to correlate with the progression of pathology (Kantarci et al., 2008; Tumati et al., 2013). 
Given the complex heterogeneity of pathological changes occurring in $\mathrm{AD}$, scientists have to increase their efforts in preclinical and clinical research to identify new therapeutics.

In the last 15 years, growing data highlighted the important genetic, epigenetic, and molecular changes occurring in $\mathrm{AD}$. These studies provided the evidence for another important actor in the drama of this neurological disorder: the marked neuroinflammation. This process is really more complex than it could appear at first glance. Indeed, neuroinflammation is generated and orchestrated by glial cells. In particular, microglia and astrocytes actively participate in mediating the so-called reactive gliosis and, by interacting with neurons, they take part in the onset and progression of the disease. Despite its recognized crucial role in $\mathrm{AD}$, the precise molecular pathways of neuroinflammation remain unclear. It is mandatory to characterize these fine mechanisms, as well as to define time, brain regions, and cell type involved in mediating this multifaceted process. Although epidemiological studies shed light on a possible benefit of long-term use of nonsteroidal antiinflammatory drugs (NSAIDs), however it could be wrongful and simplistic to suggest these drugs as the $\mathrm{AD}$ treatment, because it is erroneous to regard $\mathrm{AD}$ as a mere neuroinflammatory disease. In addition, many randomized clinical trials, designed to test the efficacy of a long-term use of NSAIDs in AD, failed to demonstrate that these drugs slow down the progression of disease or improve the symptoms in patients with early or moderate AD (Thal et al., 2005; Breitner et al., 2009; Szekely and Zandi, 2010). The reasons of these failures could be numerous; for example, the peculiar nature of the inflammatory process, the advanced state of the disease, and the dosing regimens of the trials. In this context it is also important to mention as a study demonstrated that autopsied specimens from very old humans with cognitively normal functions showed higher expression of complement factors and several immune molecules than brains from age-matched AD patients or younger people (Katsel et al., 2009). This evidence seems to suggest that molecules, typically seen as deleterious, exert simultaneously multiple roles. For example, Cyclooxygenase(COX)-2 is implicated in both physiological and pathological processes. This renders the understanding of the role of this enzyme in the brain somewhat tricky (Hoozemans et al., 2001). Unlike COX-1, which is primarily localized in human microglial cells, COX-2 is mainly expressed in pyramidal neurons where it may be involved in learning and memory functions. The importance to attenuate astroglial inflammation in $\mathrm{AD}$ has been also demonstrated by adeno-associated virus-driven suppression of the astrocyte reaction in APP/PS1 mice, which revealed improved cognition, reduced astrogliosis, and decreased $\mathrm{A} \beta$ concentrations (Furman et al., 2012).

A further important aspect that requires to be clarified concerns the temporal relationships between $A \beta$ accumulation and glial activation. Human studies have revealed a parallel increase in activation of both astrocyte and microglia and $\mathrm{AD}$ progression. This occurs independently from the $\mathrm{A} \beta$ deposition, suggesting that gliosis could per se induce neurodegeneration (Serrano-Pozo et al., 2011). Likewise, using a multitracer PET investigation in patients with $\mathrm{MCI}$ and $\mathrm{AD}$, astrocytosis was proved to be an early phenomenon in $\mathrm{AD}$ progression (Carter et al., 2012).

Therefore, the dominant view that astrocytes respond secondarily to neuronal damage could be contradicted by growing evidence supporting an active role of these cells as primary players in several mechanisms related to the pathophysiology of AD.

The interplay between dysfunctional astroglial cells and adjacent neurons can start a sequence of events that results in neuronal damage and the appearance of the characteristic AD hallmarks. Moreover, since astrocytes exert an important role in maintaining synaptic homeostasis, astrocyte malfunctioning may negatively influence the efficiency of neuronal circuits.

\section{Conclusion}

It is widely accepted that protracted astrogliosis is a prominent component of $\mathrm{AD}$ pathology and might represent an attractive therapeutic target. However, since reactive gliosis is now identified as a complex process with both helpful and detrimental aspects, it will be crucial an understanding that is not limited to phenomenological descriptions but also able to clarify the relevant disease-modifying pathways. The challenge for future studies, therefore, will be to identify tools capable of selectively prevent the over-activation of these cells and pathways without interfering with their physiological and beneficial properties. Currently a fair number of compounds seems to be able to restore a normal astrocyte functioning in $\mathrm{AD}$ models, serving as novel potential tools in the treatment of $\mathrm{AD}$ pathology (Scuderi et al., 2014a,b).

\section{Author Contributions}

MRB, AI and LS Jr. drafted the manuscript. CS, GE, and LS revised and approved the final version of the manuscript. All authors ensure that questions related to the accuracy or integrity of any part of the work were appropriately investigated and resolved.

\section{Acknowledgments}

This work was supported by the Italian Ministry of Instruction, University and Research grants (MIUR; PON01-02512 and PRIN prot. 2012 WBSSY4_006). 


\section{References}

Abbas, N., Bednar, I., Mix, E., Marie, S., Paterson, D., Ljungberg, A., et al. (2002). Up-regulation of the inflammatory cytokines IFN-gamma and IL-12 and downregulation of IL-4 in cerebral cortex regions of APP(SWE) transgenic mice. J. Neuroimmunol. 126, 50-57. doi: 10.1016/S0165-5728(02)00050-4

Abramov, A. Y., Canevari, L., and Duchen, M. R. (2004). Calcium signals induced by amyloid beta peptide and their consequences in neurons and astrocytes in culture. Biochim. Biophys. Acta. 1742, 81-87. doi: 10.1016/j.bbamcr.2004.09.006

Alzheimer, A. (1907). Uber eine eigenartige Erkrankung der Hirnrinde. Allg. Z. Psychiat. Psych-Gerichtl. Med. 64, 146-148.

Armstrong, R. A. (2009). The molecular biology of senile plaques and neurofibrillary tangles in Alzheimer's disease. Folia Neuropathol. 47, 289-299.

Bales, K. R., Du, Y., Dodel, R. C., Yan, G. M., Hamilton-Byrd, E., and Paul, S. M. (1998). The NF-kappaB/Rel family of proteins mediates Abeta-induced neurotoxicity and glial activation. Brain Res. Mol. Brain Res. 57, 63-72. doi: 10.1016/S0169-328X(98)00066-7

Bélanger, M., and Magistretti, P. J. (2009). The role of astroglia in neuroprotection. Dialogues Clin. Neurosci. 11, 281-295.

Blennow, K., de Leon, M. J., and Zetterberg, H. (2006). Alzheimer's disease. Lancet 368, 387-403. doi: 10.1016/S0140-6736(06)69113-7

Block, M. L., and Hong, J. S. (2005). Microglia and inflammation-mediated neurodegeneration: multiple triggers with a common mechanism. Prog. Neurobiol. 76, 77-98. doi: 10.1016/j.pneurobio.2005.06.004

Breitner, J. C., Haneuse, S. J., Walker, R., Dublin, S., Crane, P. K., Gray, S. L., et al. (2009). Risk of dementia and $\mathrm{AD}$ with prior exposure to NSAIDs in an elderly community-based cohort. Neurology 72, 1899-1905. doi: 10.1212/WNL.0b013e3181a18691

Carter, S. F., Schöll, M., Almkvist, O., Wall, A., Engler, H., Långström, B., et al. (2012). Evidence for astrocytosis in prodromal Alzheimer disease provided by $11 \mathrm{C}$-deuterium-L-deprenyl: a multitracer PET paradigm combining $11 \mathrm{C}$ Pittsburgh compound B and 18F-FDG. J. Nucl. Med. 53, 37-46. doi: 10.2967/jnumed.110.087031

Chow, S. K., Yu, D., Macdonald, C. L., Buibas, M., and Silva, G. A. (2010). Amyloid $\beta$-peptide directly induces spontaneous calcium transients, delayed intercellular calcium waves and gliosis in rat cortical astrocytes. ASN Neuro 2:e00026. doi: 10.1042/AN20090035

Craft, J. M., Watterson, D. M., and Van Eldik, L. J. (2006). Human amyloid betainduced neuroinflammation is an early event in neurodegeneration. Glia 53, 484-490. doi: 10.1002/glia.20306

Craft, J. M., Watterson, D. M., Marks, A., and van Eldik, L. J. (2005). Enhanced susceptibility of S-100B transgenic mice to neuroinflammation and neuronal dysfunction induced by intracerebroventricular infusion of human betaamyloid. Glia 51, 209-216. doi: 10.1002/glia.20194

Deitmer, J. W., and Rose, C. R. (1996). pH regulation and proton signalling by glial cells. Prog. Neurobiol. 48, 73-103. doi: 10.1016/0301-0082(95)00039-9

Doens, D., and Fernández, P. L. (2014). Microglia receptors and their implications in the response to amyloid $\beta$ for Alzheimer's disease pathogenesis. J. Neuroinflammation 11:48. doi: 10.1186/1742-2094-11-48

Donato, R. (2003). Intracellular and extracellular roles of S100 proteins. Microsc. Res. Tech. 60, 540-551. doi: 10.1002/jemt.10296

Esposito, G., De Filippis, D., Steardo, L., Scuderi, C., Savani, C., Cuomo, V., et al. (2006). CB1 receptor selective activation inhibits beta-amyloid-induced iNOS protein expression in C6 cells and subsequently blunts tau protein hyperphosphorylation in co-cultured neurons. Neurosci. Lett. 404, 342-346. doi: 10.1016/j.neulet.2006.06.012

Frank-Cannon, T. C., Alto, L. T., McAlpine, F. E., and Tansey, M. G. (2009). Does neuroinflammation fan the flame in neurodegenerative diseases? Mol. Neurodegener. 4:47. doi: 10.1186/1750-1326-4-47

Fröhlich, N., Nagy, B., Hovhannisyan, A., and Kukley, M. (2011). Fate of neuronglia synapses during proliferation and differentiation of NG2 cells. J. Anat. 219, 18-32. doi: 10.1111/j.1469-7580.2011.01392.x

Funato, H., Yoshimura, M., Yamazaki, T., Saido, T. C., Ito, Y., Yokofujita, J., et al. (1998). Astrocytes containing amyloid beta-protein (Abeta)-positive granules are associated with Abeta40-positive diffuse plaques in the aged human brain. Am. J. Pathol. 152, 983-992.

Furman, J. L., Sama, D. M., Gant, J. C., Beckett, T. L., Murphy, M. P., Bachstetter, A. D., et al. (2012). Targeting astrocytes ameliorates neurologic changes in a mouse model of Alzheimer's disease. J. Neurosci. 32, 16129-16140. doi: 10.1523/JNEUROSCI.2323-12.2012

Gerlai, R. (1998). A new continuous alternation task in T-maze detects hippocampal dysfunction in mice. A strain comparison and lesion study. Behav. Brain Res. 95, 91-101. doi: 10.1016/S0166-4328(97)00214-3

Glass, C. K., Saijo, K., Winner, B., Marchetto, M. C., and Gage, F. H. (2010). Mechanisms underlying inflammation in neurodegeneration. Cell 140, 918-934. doi: 10.1016/j.cell.2010.02.016

Goedert, M., and Spillantini, M. G. (2006). A century of Alzheimer's disease. Science 314, 777-781. doi: 10.1126/science.1132814

Gundersen, V., Storm-Mathisen, J., and Bergersen, L. H. (2015). Neuroglial transmission. Physiol. Rev. 95, 695-726. doi: 10.1152/physrev.00024.2014

Hol, E. M., and Pekny, M. (2015). Glial fibrillary acidic protein (GFAP) and the astrocyte intermediate filament system in diseases of the central nervous system. Curr. Opin. Cell Biol. 32, 121-130. doi: 10.1016/j.ceb.2015.02.004

Hoozemans, J. J., Rozemuller, A. J., Janssen, I., De Groot, C. J., Veerhuis, R., and Eikelenboom, P. (2001). Cyclooxygenase expression in microglia and neurons in Alzheimer's disease and control brain. Acta Neuropathol. 101, 2-8. doi: $10.1007 /$ s004010000251

Huang, H. C., and Jiang, Z. F. (2009). Accumulated amyloid-beta peptide and hyperphosphorylated tau protein: relationship and links in Alzheimer's disease. J. Alzheimers Dis. 16, 15-27. doi: 10.3233/JAD-2009-0960

Iadecola, C., and Nedergaard, M. (2007). Glial regulation of the cerebral microvasculature. Nat. Neurosci. 10, 1369-1376. doi: 10.1038/ nn2003

Kantarci, K., Knopman, D. S., Dickson, D. W., Parisi, J. E., Whitwell, J. L., Weigand, S. D., et al. (2008). Alzheimer disease: postmortem neuropathologic correlates of antemortem 1H MR spectroscopy metabolite measurements. Radiology 248, 210-220. doi: 10.1148/radiol.2481071590

Katsel, P., Tan, W., and Haroutunian, V. (2009). Gain in brain immunity in the oldest-old differentiates cognitively normal from demented individuals. PLoS ONE 4:e7642. doi: 10.1371/journal.pone.0007642

Koistinaho, M., Lin, S., Wu, X., Esterman, M., Koger, D., Hanson, J., et al. (2004). Apolipoprotein E promotes astrocyte colocalization and degradation of deposited amyloid-beta peptides. Nat. Med. 10, 719-726. doi: 10.1038/nm1058

Li, R., Strohmeyer, R., Liang, Z., Lue, L. F., and Rogers, J. (2004b). CCAAT/enhancer binding protein delta (C/EBPdelta) expression and elevation in Alzheimer's disease. Neurobiol. Aging 25, 991-999. doi: 10.1016/j.neurobiolaging.2003.10.016

Li, R., Yang, L., Lindholm, K., Konishi, Y., Yue, X., Hampel, H., et al. (2004a). Tumor necrosis factor death receptor signaling cascade is required for amyloid-beta protein-induced neuron death. J. Neurosci. 24, 1760-1771. doi: 10.1523/JNEUROSCI.4580-03.2004

Li, Y., Liu, L., Barger, S. W., and Griffin, W. S. (2003). Interleukin-1 mediates pathological effects of microglia on tau phosphorylation and on synaptophysin synthesis in cortical neurons through a p38-MAPK pathway. J. Neurosci. 23, $1605-1611$.

Lukiw, W. J., and Bazan, N. G. (2000). Neuroinflammatory signaling upregulation in Alzheimer's disease. Neurochem. Res. 25, 1173-1184. doi: 10.1023/A:1007627725251

Lynch, A. M., and Lynch, M. A. (2002). The age-related increase in IL-1 type I receptor in rat hippocampus is coupled with an increase in caspase-3 activation. Eur. J. Neurosci. 15, 1779-1788. doi: 10.1046/j.1460-9568.2002.02012.x

Malchiodi-Albedi, F., Domenici, M. R., Paradisi, S., Bernardo, A., Ajmone-Cat, M. A., and Minghetti, L. (2001). Astrocytes contribute to neuronal impairment in beta A toxicity increasing apoptosis in rat hippocampal neurons. Glia 34, 68-72. doi: 10.1002/glia.1041

Medeiros, R., and LaFerla, F. M. (2013). Astrocytes: conductors of the Alzheimer disease neuroinflammatory symphony. Exp. Neurol. 239, 133-138. doi: 10.1016/j.expneurol.2012.10.007

Moynagh, P. N. (2005). The interleukin-1 signalling pathway in astrocytes: a key contributor to inflammation in the brain. J. Anat. 207, 265-269. doi: 10.1111/j.1469-7580.2005.00445.x

Mrak, R. E., and Griffin, W. S. (2001). The role of activated astrocytes and of the neurotrophic cytokine S100B in the pathogenesis of Alzheimer's disease. Neurobiol. Aging 22, 915-922. doi: 10.1016/S0197-4580(01)00293-7

Mrak, R. E., Sheng, J. G., and Griffin, W. S. (1996). Correlation of astrocytic S100 beta expression with dystrophic neurites in amyloid plaques of Alzheimer's 
disease. J. Neuropathol. Exp. Neurol. 55, 273-279. doi: 10.1097/00005072199603000-00002

Mulder, S. D., Veerhuis, R., Blankenstein, M. A., and Nielsen, H. M. (2012). The effect of amyloid associated proteins on the expression of genes involved in amyloid- $\beta$ clearance by adult human astrocytes. Exp. Neurol. 233, 373-379. doi: 10.1016/j.expneurol.2011.11.001

Nagele, R. G., D’Andrea, M. R., Lee, H., Venkataraman, V., and Wang, H. Y. (2003). Astrocytes accumulate A beta 42 and give rise to astrocytic amyloid plaques in Alzheimer disease brains. Brain Res. 971, 197-209. doi: 10.1016/S00068993(03)02361-8

Nishiyama, H., Knopfel, T., Endo, S., and Itohara, S. (2002). Glial protein S100B modulates long-term neuronal synaptic plasticity. Proc. Natl. Acad. Sci. U.S.A. 99, 4037-4042. doi: 10.1073/pnas.052020999

Obara, M., Szeliga, M., and Albrecht, J. (2008). Regulation of $\mathrm{pH}$ in the mammalian central nervous system under normal and pathological conditions: facts and hypotheses. Neurochem. Int. 52, 905-919. doi: 10.1016/j.neuint.2007.10.015

Öngür, D., Bechtholt, A. J., Carlezon, W. A. Jr., and Cohen, B. M. (2014). Glial abnormalities in mood disorders. Harv. Rev. Psychiatry 22, 334-337. doi: 10.1097/HRP.0000000000000060

Pekny, M., Wilhelmsson, U., and Pekna, M. (2014). The dual role of astrocyte activation and reactive gliosis. Neurosci. Lett. 565, 30-38. doi: 10.1016/j.neulet.2013.12.071

Perea, G., Navarrete, M., and Araque, A. (2009). Tripartite synapses: astrocytes process and control synaptic information. Trends Neurosci. 32, 421-431. doi: 10.1016/j.tins.2009.05.001

Querfurth, H. W., and LaFerla, F. M. (2010). Alzheimer's disease. N. Engl. J. Med. 362, 329-344. doi: 10.1056/NEJMra0909142

Ransohoff, R. M., and Brown, M. A. (2012). Innate immunity in the central nervous system. J. Clin. Invest. 122, 1164-1171. doi: 10.1172/JCI58644

Rodríguez, J. J., Olabarria, M., Chvatal, A., and Verkhratsky, A. (2009). Astroglia in dementia and Alzheimer's disease. Cell Death Differ. 16, 378-385. doi: $10.1038 /$ cdd. 2008.172

Rodríguez-Arellano, J. J., Parpura, V., Zorec, R., and Verkhratsky, A. (2015). Astrocytes in physiological aging and Alzheimer's disease. Neuroscience pii: S0306-4522(15)00031-7. doi: 10.1016/j.neuroscience.2015.01.007

Rossi, D. (2015). Astrocyte physiopathology: at the crossroads of intercellular networking, inflammation and cell death. Prog. Neurobiol. 130, 86-120. doi: 10.1016/j.pneurobio.2015.04.003

Scuderi, C., Esposito, G., Blasio, A., Valenza, M., Arietti, P., Steardo, L. Jr., et al. (2011). Palmitoylethanolamide counteracts reactive astrogliosis induced by $\beta$-amyloid peptide. J. Cell. Mol. Med. 15, 2664-2674. doi: 10.1111/j.15824934.2011.01267.x

Scuderi, C., Steardo, L., and Esposito, G. (2014b). Cannabidiol promotes amyloid precursor protein ubiquitination and reduction of beta amyloid expression in SHSY5YAPP+ cells through PPAR $\gamma$ involvement. Phytother. Res. 28, 1007-1013. doi: 10.1002/ptr.5095

Scuderi, C., Stecca, C., Iacomino, A., and Steardo, L. (2013). Role of astrocytes in major neurological disorders: the evidence and implications. IUBMB Life 65, 957-961. doi: 10.1002/iub.1223

Scuderi, C., Stecca, C., Valenza, M., Ratano, P., Bronzuoli, M. R., Bartoli, S., et al. (2014a). Palmitoylethanolamide controls reactive gliosis and exerts neuroprotective functions in a rat model of Alzheimer's disease. Cell Death Dis. 5:e1419. doi: 10.1038/cddis.2014.376

Scuderi, C., Valenza, M., Stecca, C., Esposito, G., Carratù, M. R., and Steardo, L. (2012). Palmitoylethanolamide exerts neuroprotective effects in mixed neuroglial cultures and organotypic hippocampal slices via peroxisome proliferator-activated receptor- $\alpha$. J. Neuroinflammation 9:49. doi: 10.1186/1742-2094-9-49

Selkoe, J. (1996). Amyloid beta-protein and the genetics of Alzheimer's disease. J. Biol. Chem. 271, 18295-18298. doi: 10.1074/jbc.271.31.18295

Serrano-Pozo, A., Mielke, M. L., Gómez-Isla, T., Betensky, R. A., Growdon, J. H., Frosch, M. P., et al. (2011). Reactive glia not only associates with plaques but also parallels tangles in Alzheimer's disease. Am. J. Pathol. 179, 1373-1384. doi: 10.1016/j.ajpath.2011.05.047

Sheng, J. G., Mrak, R. E., Bales, K. R., Cordell, B., Paul, S. M., Jones, R. A., et al. (2000). Overexpression of the neuritotrophic cytokine S100beta precedes the appearance of neuritic beta-amyloid plaques in APPV717F mice. J. Neurochem. 74, 295-301. doi: 10.1046/j.1471-4159.2000.0740295.x

Sofroniew, M. V. (2014). Astrogliosis. Cold Spring Harb. Perspect. Biol. 7:a020420. doi: $10.1101 /$ cshperspect.a020420

Sofroniew, M. V., and Vinters, H. V. (2010). Astrocytes: biology and pathology. Acta Neuropathol. 119, 7-35. doi: 10.1007/s00401-009-0619-8

Solenski, N. J., Kostecki, V. K., Dovey, S., and Periasamy, A. (2003). Nitric-oxideinduced depolarization of neuronal mitochondria: implications for neuronal cell death. Mol. Cell. Neurosci. 24, 1151-1169. doi: 10.1016/j.mcn.2003.08.011

Sun, D., and Jakobs, T. C. (2012). Structural remodeling of astrocytes in the injured CNS. Neuroscientist 18, 567-588. doi: 10.1177/1073858411423441

Szekely, C. A., and Zandi, P. P. (2010). Non-steroidal anti-inflammatory drugs and Alzheimer's disease: the epidemiological evidence. CNS Neurol. Disord. Drug Targets 9, 132-139. doi: 10.2174/187152710791012026

Thal, L. J., Ferris, S. H., Kirby, L., Block, G. A., Lines, C. R., Yuen, E., et al. (2005). A randomized, double-blind, study of rofecoxib in patients with mild cognitive impairment. Neuropsychopharmacology 30, 1204-1215. doi: 10.1038/sj.npp.1300690

Tumati, S., Martens, S., and Aleman, A. (2013). Magnetic resonance spectroscopy in mild cognitive impairment: systematic review and meta-analysis. Neurosci. Biobehav. Rev. 37, 2571-2586. doi: 10.1016/j.neubiorev.2013.08.004

Tuppo, E. E., and Arias, H. R. (2005). The role of inflammation in Alzheimer's disease. Int. J. Biochem. Cell Biol. 37, 289-305. doi: 10.1016/j.biocel.2004.07.009

Verkhratsky, A., and Butt, A. M. (2013). Glial Physiology and Pathophysiology. Chichester: Wiley-Blackwell. doi: 10.1002/9781118402061

Verkhratsky, A., and Parpura, V. (2015). Astrogliopathology in neurological, neurodevelopmental and psychiatric disorders. Neurobiol. Dis. pii: S09699961(15)00103-5. doi: 10.1016/j.nbd.2015.03.025

Verkhratsky, A., Rodríguez, J. J., and Steardo, L. (2014). Astrogliopathology: a central element of neuropsychiatric diseases? Neuroscientist 20, 576-588. doi: $10.1177 / 1073858413510208$

Walhovd, K. B., Johansen-Berg, H., and Káradóttir, R. T. (2014). Unraveling the secrets of white matter-bridging the gap between cellular, animal and human imaging studies. Neuroscience 276, 2-13. doi: 10.1016/j.neuroscience.2014.06.058

Welsh-Bohmer, K. A., White, C. L. III. (2009). Alzheimer disease: what changes in the brain cause dementia? Neurology 72:e21. doi: 10.1212/01.wnl.0000343818.11392.d9

Wilson, J. X. (1997). Antioxidant defense of the brain: a role for astrocytes. Can. J. Physiol. Pharmacol. 75, 1149-1163. doi: 10.1139/y97-146

Wyss-Coray, T., Loike, J. D., Brionne, T. C., Lu, E., Anankov, R., Yan, F., et al. (2003). Adult mouse astrocytes degrade amyloid-beta in vitro and in situ. Nat. Med. 9, 453-457. doi: 10.1038/nm838

Zhao, J., O'Connor, T., and Vassar, R. (2011). The contribution of activated astrocytes to $\mathrm{A} \beta$ production: implications for Alzheimer's disease pathogenesis. J. Neuroinflammation 8:150. doi: 10.1186/1742-2094-8-150

Conflict of Interest Statement: The authors declare that the research was conducted in the absence of any commercial or financial relationships that could be construed as a potential conflict of interest.

Copyright (c) 2015 Steardo, Bronzuoli, Iacomino, Esposito, Steardo and Scuderi. This is an open-access article distributed under the terms of the Creative Commons Attribution License (CC BY). The use, distribution or reproduction in other forums is permitted, provided the original author(s) or licensor are credited and that the original publication in this journal is cited, in accordance with accepted academic practice. No use, distribution or reproduction is permitted which does not comply with these terms. 